\title{
THREE-DIMENSIONAL ANALYSIS AND NUMERICAL OPTIMIZATION OF COMBINED NATURAL CONVECTION AND RADIATION HEAT LOSS IN SOLAR CAVITY RECEIVER WITH PLATE FINS INSERT
}

\author{
L. C. Ngo ${ }^{1}$, T. Bello-Ochende ${ }^{2 *}$ and J. P. Meyer ${ }^{1}$ \\ 1 Department of Mechanical and Aeronautical Engineering, University of Pretoria, Pretoria, Private Bag X20, Hatfield 0028, South Africa \\ 2 Department of Mechanical Engineering, University of Cape Town, Private Bag X3, Rondebosch 7701, Cape Town, South Africa
}

\begin{abstract}
The numerical study and optimization of combined laminar natural convection and surface radiation heat transfer in solar cavity receiver with plate fins is presented in this paper. Minimizing heat loss in cavity receivers is seen as an effective way to enhance the thermal performance and the use of plate fins has been proposed as a low cost means to minimize heat loss. Firstly, the influence of operating temperature, emissivity of the surface, orientation and the geometric parameters on the total heat loss from the receiver was investigated. It was observed that convective heat loss is largely affected by the angle of inclination of the receiver, the presence of fins and the number of fins in the receiver. As for the radiation heat loss it was observed that it is mainly influenced by the properties of the cavity receiver surface. The radiation heat loss was found to be constant at all the angles of the receiver. Significant reduction in natural convection heat loss from the cavity receiver was accomplished by using the plate fins whereas radiation heat loss was marginally reduced by about $5 \%$. Secondly, the optimization was conducted to obtain the optimal fin geometry and lastly, the overall thermal efficiency of the receiver was presented at different operating temperatures. The overall cavity efficiency marginally increased by approximately $2 \%$ with the insertion of fin plates although the convective heat loss was suppressed by about $20 \%$. This is due to the fact that radiation heat loss dominates at high operating temperatures compared to convective heat loss.
\end{abstract}

KEY WORDS: Parabolic dish; Cavity receiver; Natural convection; Radiation; plate fin; Optimization

*Corresponding Author: tbochende@gmail.com 


\section{Nomenclature}

\begin{tabular}{|c|c|}
\hline \multicolumn{2}{|c|}{ Alphabetical Symbols } \\
\hline$A$ & Surface area, $\mathrm{m}^{2}$ \\
\hline$D$ & Cavity diameter, $\mathrm{m}$ \\
\hline$d$ & Aperture diameter, $\mathrm{m}$ \\
\hline$C_{p}$ & Specific heat capacity, J/(kg.K) \\
\hline$h_{c}$ & Convective heat transfer coefficient, $\mathrm{W} /\left(\mathrm{m}^{2} \mathrm{~K}\right)$ \\
\hline$h_{R}$ & Radiative heat transfer coefficient, $\mathrm{W} /\left(\mathrm{m}^{2} \mathrm{~K}\right)$ \\
\hline$H$ & Plate fin height, $\mathrm{m}$ \\
\hline$H / W$ & Dimensionless plate fin height \\
\hline$J$ & Joules \\
\hline$J$ & Radiosity, \\
\hline$K$ & Kelvin \\
\hline$F$ & View factor \\
\hline$F$ & Flux, $\mathrm{W} / \mathrm{m}^{2}$ \\
\hline$k$ & Thermal conductivity, $\mathrm{W} /(\mathrm{mK})$ \\
\hline $\mathrm{kg}$ & Kilogram \\
\hline $\mathrm{m}$ & Meter \\
\hline$N$ & Number of fins \\
\hline$N$ & Number of surfaces \\
\hline$N u$ & Nusselt number \\
\hline$P$ & Power, W \\
\hline$p$ & Pressure, $\mathrm{Pa}$ \\
\hline $\operatorname{Pr}$ & Prandtl number \\
\hline $\mathrm{Pa}$ & Pascal \\
\hline$q$ & Energy flux, $\mathrm{W} / \mathrm{m}^{2}$ \\
\hline$Q$ & Heat loss, W \\
\hline$R a$ & Raleigh number \\
\hline
\end{tabular}


S

$t$

$t / W$

$T$

$T_{s}$

V

W

X

Greek symbols

$\alpha$

$\varphi$

$\rho$

$\mu$

$\varepsilon$

$\sigma$

$\eta$

$\lambda$

Subscript

$c$

eff

$R$

$s$

$\infty$

Abbreviation

S2S

CFD
Fin space, $\mathrm{m}$

Plate fin thickness, $\mathrm{m}$

Dimensionless plate fin thickness

Temperature, $\mathrm{K}$

Surface temperature, K

Velocity vector, $\mathrm{m} / \mathrm{s}$

Watt

Mass force vector, $\mathrm{N} / \mathrm{kg}$

Absorptance

Receiver inclination angle, degree

Density of air, $\mathrm{kg} / \mathrm{m}^{3}$

Dynamic viscosity, $\mathrm{kg} /(\mathrm{m} . \mathrm{s})$

Emissivity

Stefan-Boltzmann constant, $\mathrm{W} / \mathrm{m}^{2} . \mathrm{K}^{4}$

Efficiency

Standard deviation

Convection

Effectiveness

Radiation

Surface

Ambient

Surface-to-Surface

Computational Fluid Dynamics 


\section{INTRODUCTION}

The total energy loss of solar receivers plays an important role in the light-heat conversion. It is comprised of conduction heat loss through the cavity receiver housing, convection and radiation heat losses to the ambient through the aperture. However, most of the heat loss is mainly through natural convection and surface radiation since the cavity receiver is insulated and as such it is very important to understand the behavior of this type of heat transfer mechanisms.

Research of heat transfer and flow in the cavity receivers can greatly contribute to the estimation of the thermal performance and optimization of the design [1]-[3]. A literature review indicates that numerous studies have been conducted on natural convection heat loss in open cavities [4]-[11].

Some numerical and experimental investigations on combined natural convection and radiation heat transfer in cavities have been carried out by researchers. With regards to numerical studies, Lin et al. [12] numerically investigated the steady turbulent free convection in a two-dimensional open square cavity with and without surface radiation. Balaji and Venkateshan [13] presented results of a numerical study for natural convection and radiation heat transfer and observed that the results that included radiation were more realistic. Singh and Venkateshan [14] reported numerical results of a study of natural convection and surface radiation heat transfer for a two-dimensional open cavity using air as the fluid medium. They observed that surface radiation altered the flow patterns and the thermal performance significantly.

Hinojosa et al. [15] conducted a numerical analysis of both natural convection and radiation heat transfer in a titled 2D open cavity. They observed that cavity receiver inclination angle significantly influences the convective Nusselt number and not the radiation Nusselt number. Hinojosa et al. [16] 
used the Boussinesq approximation in the numerical study of natural convection and surface thermal radiation in an open cavity. Reddy and Sendhil Kumar [17] reported numerical results of natural convection and radiation heat transfer in a modified cavity receiver. Using asymptotic computational fluid dynamics approach Sendhil Kumar [18] numerically investigated combined natural convection and radiation heat loss from a modified cavity receiver.

Gonzalez et al. [19] presented numerical results for natural convection and radiation heat transfer with variable properties and large temperature differences in a square cavity receiver. They observed that the radiation heat transfer is more important than convective heat transfer at larger temperature gradients.

In terms of experimental studies, Ramesh and Merzkirch [20] experimentally studied the interaction of natural convection and surface radiation heat transfer on side-vented open cavities. They presented results highlighting the effect of interaction and concluded that the surface emissivity had a huge effect on temperature and flow patterns. Tan et al. [21] conducted experiments to investigate the heat loss of semi-spherical cavity with fluid inlet temperatures from $348 \mathrm{~K}$ to $423 \mathrm{~K}$.

Minimizing heat loss is seen as an effective way to enhance the thermal performance of cavity receivers. Some research have been conducted on the reduction of heat loss from cavity receivers. However, fewer studies have been done on cavity enhancement, performance and optimization. And most of these studies used the Boussinesq approximation in the analysis. Kribus et al. [22] designed and demonstrated the operation of the multistage receiver under elevated temperatures, which separated the aperture into different stages depending to the irradiation distribution. This was aimed at reducing heat losses and they achieved exit temperatures of up to $1000{ }^{\circ} \mathrm{C}$. 
Hahm et al. [23] compared the performance of a single cavity receiver with solar cavity receiver combined with a fabricated cone concentrator. They observed large amounts of heat rejection with smaller exit aperture size for the cone concentrator. On the other hand thermal losses increased with larger exit aperture size of the cavity and therefore optimum cone geometry is essential. Le Roux et al. [24] optimally sized a modified cavity receiver for maximum power using the second law of thermodynamics.

Karni et al. [25] designed a volumetric solar receiver, nicknamed Porcupine. They demonstrated the capability of the Porcupine to endure concentrated solar flux of up to $4 \mathrm{MW} / \mathrm{m}^{2}$ and producing exit working fluid temperatures of up to $940{ }^{\circ} \mathrm{C}$. Chen et al. [26] designed a novel linear cavity absorber and investigated its thermal performance. They observed that this cavity absorber performed better under medium temperatures. Reddy and Kumar [17] compared the thermal performance of the cavity receiver with extended reflectors of different geometries (CPC, cone and trumpet). They observed better performance from the trumpet one compared to the other ones. A glass covered cavity receiver was presented by Cui et al. [27]. The aim of using the glass cover was to separate the ambient air from the inner cavity receiver thus reducing both the natural convection and radiation heat loss.

Most of the earlier studies used 2D numerical model and the Boussinesq approximation. However, at higher temperature the Boussisneq approximation does not provide accurate results. In this study, a 3D numerical model of a modified cavity receiver with fin plates has been developed and investigated for combined laminar natural convection and surface radiation heat loss using the nonBoussinesq method. The effect of surface emissivity, operating temperature, orientation and the geometric parameters on the total heat loss from the receiver was investigated. The optimization was conducted to obtain the optimal fin geometry and the overall thermal efficiency of the receiver 
was presented at different operating temperatures. In this paper, the analysis is based on parabolic dish/cavity receiver system operating at temperatures between $800 \mathrm{~K}$ and $1200 \mathrm{~K}$.

\section{PHYSICAL AND MATHEMATICAL MODEL}

Fig.1a shows the schematics of the cavity receiver proposed by Kumar and Reddy [7] and Fig.1b the proposed cavity with plate fins in two-dimension. The cavity receiver is usually fitted at the focus of the parabolic dish concentrator to capture concentrated sunlight from the dish. Both cavity receivers are made of copper tubing with an opening aperture diameter $(d)$ and cavity diameter $(D)$. Circular plate fins ranging between $1 \mathrm{~mm}$ and $6 \mathrm{~mm}$ have been installed in the proposed cavity receiver (Fig.1b) to suppress combined laminar natural convection and radiation heat loss. The cavity receiver diameter and the aperture are given as $180 \mathrm{~mm}$ and $100 \mathrm{~mm}$ respectively. In order to get the geometry of the cavity receiver, the pipes (made of copper) are wound spirally. An opaque insulating material is used to cover the outer surface of the cavity receiver so as to reduce conduction heat loss. Some assumptions are made for modelling the cavity receiver: (a) there is maximum and uniform solar flux distribution inside the cavity receiver (b) the surfaces are considered smooth and uniform for the original modified cavity receiver as shown in Fig. 1a; (c) the plate fins are made of copper and are installed on the smooth inner aperture surface of the original modified cavity receiver as shown in Fig. 1b; (d) the temperature of copper tube surface is equivalent to temperature of air flowing in it. However, the copper tubes were not included in the simulation; (e) effects of wind are not considered (i.e. no wind case).

The hydrodynamic performance of plate fins are significantly influenced by design variables, namely the geometric parameters fin heights $\left(H_{1}, H_{2}\right.$, and $\left.H_{3}\right)$ the fin thickness $\left(t_{1}, t_{2}\right.$ and $\left.t_{3}\right)$ and the number of fins $N$ as depicted in Figure $1 \mathrm{~b}$. The fin height and thickness are defined as 
dimensionless parameters $H_{j} / W$ and $t_{j} / W$ respectively in this study (for $j=1,2,3$ ). The dimensionless fin heights were varied in the following range: $0.025 \leq H_{j} / W \leq 0.15$. The dimensionless thicknesses of the fins were varied in the range: $0.025 \leq t_{j} / W \leq 0.125$ and the value of $N$ was varied from zero to three, where $N=0$ indicate no fin condition. In this study the effects of the distance between two plate fins $S$ was not considered.

Fig. 2 shows the cavity receiver at the different inclinations angle used in this study. Fig. 2 a depicts the cavity receiver at ideal sunrise when the parabolic dish is facing eastwards and therefore, the cavity receiver aperture facing westwards. Fig. 2 b depicts the cavity receiver at noon when the sun is directly above both the parabolic dish and cavity receiver. And Fig. 2c is a depiction of the receiver at an ideal sun set when the parabolic dish is facing westwards and the cavity receiver aperture in the opposite direction.

In this study, the flow considered is assumed to be three-dimensional, steady and laminar. The heat transfer and flow simulations for natural convection in the cavity receiver are based on simultaneous solution of the equations describing the conservation of mass, momentum and energy of the system. The vector form of the continuity, momentum and energy equations is written as:

Continuity equation:

$\Delta \cdot(\rho \mathbf{V})=0$

Momentum equation:

$\mathbf{V} \cdot \nabla(\rho \mathbf{V})=\rho \mathbf{X}-\nabla p+\nabla^{2}(\mu \mathbf{V})$ 
Energy equation:

$\mathbf{V} \cdot \nabla\left(\rho c_{p} T\right)=\nabla^{2}(k T)$

where $\rho$ is the density of air, $\mathrm{kg} / \mathrm{m}^{3}, \mathbf{V}$ is the velocity vector of air, $\mathrm{m} / \mathrm{s}, \mathbf{X}$ is the mass force vector, $\mathrm{N} / \mathrm{kg}, \quad p$ is the pressure, $\mathrm{Pa}, \mu$ is dynamic viscosity, $\mathrm{kg} /(\mathrm{m} . \mathrm{s}), c_{p}$ is the specific heat capacity at constant pressure, $\mathrm{J} /(\mathrm{kg} . \mathrm{K}), k$ is thermal conductivity of air, $\mathrm{W} /(\mathrm{m} . \mathrm{K})$ and $T$ is temperature in Kelvin.

Since temperatures encountered in concentrated solar thermal systems are high, the Boussinesq approximation is considered not to be appropriate [11] and as such is not used in this study. To account for the variation of air properties with temperature, polynomial relationships for specific heat capacity at constant pressure, density, dynamic viscosity and thermal conductivity are used in this study [28].

$c_{p}=1.3864 \times 10^{-13} T^{4}-6.4747 \times 10^{-10} T^{3}+1.0234 \times 10^{-6} T^{2}-4.3282 \times 10^{-4} T+1.0613$

$\rho=7.4992 \times 10^{-9} T^{3}+1.6487 \times 10^{-5} T^{2}-1.2366 \times 10^{-2} T+3.6508$

$\mu=1.3864 \times 10^{-15} T^{3}-1.4346 \times 10^{-11} T^{2}+5.0523 \times 10^{-8} T+4.1130 \times 10^{-6}$

$k=1.5797 \times 10^{-17} T^{5}+9.4600 \times 10^{-14} T^{4}+2.2012 \times 10^{-10} T^{2}-2.3758 \times 10^{-7} T^{2}$

$+1.7082 \times 10^{-4} T^{2}-7.488 \times 10^{-3}$ 
The convective heat transfer coefficient can be expressed as:

$h_{c}=\frac{N u k}{D}$

where $N u$ is the Nusselt number and $D$ is the cavity receiver diameter. The Nusselt numbers were calculated using CFD code and were evaluated as scalar field functions for the inner and aperture surfaces of the cavity receiver for both cases (with and without fins). Natural convection heat loss from the cavity receiver is expressed as:

$Q_{c}=h_{c} A\left(T_{s}-T_{\infty}\right)$

The non-Boussinesq laminar natural convection model is solved using the continuity, momentum and energy equations. The radiation heat transfer in the surfaces of the cavity receiver is accounted for by using the Surface-to-Surface (S2S) model which is coupled with the laminar natural convection model. In this model the medium (air in this case) that fills the space between the surfaces is considered as non-participating. That is, it does not absorb, emit or scatter radiation. Under these circumstances, the radiation properties and the thermal boundary conditions that are imposed on each surface uniquely define the amount of radiation that a surface receives and emits. The surface properties are quantified in terms of emissivity, reflectivity, transmissivity and radiation temperature.

The size, orientation and separation distance between two surfaces are the parameters that effect energy exchange between them. The view factor which is calculated using the view factor model is used to account for the effects of these parameters. 
The influence of natural convection and radiation heat transfer on total heat transfer was predicted by varying the emissivity of the cavity receiver surfaces from 0.2 to 1.0 . From a specified surface, the radiant power comprises of directly emitted and reflected energy. The energy reflected from surface $i$ is expressed as [29]:

$q_{\text {out }, i}=\varepsilon_{i} \sigma T_{i}^{4}+\left(1-\varepsilon_{i}\right) q_{\text {in, } i}$

The view factor, $F_{j i}$ is a function of the amount of incident energy onto a surface from another surface. The incident energy flux $q_{i, i}$ can be expressed in terms of the energy flux leaving all other surfaces as [29]:

$A_{i} q_{i n, i}=\sum_{j=1}^{N} A_{j} q_{o u t, j} F_{j i}$

The view factor reciprocity formula for $N$ surfaces is given as:

$A_{j} F_{j i}=A_{i} F_{i j}$

Therefore, $q_{i n, i}$ is expressed as:

$q_{i n, i}=\sum_{j=1}^{N} F_{i j} q_{o u t, j}$

When Eq. (13) is substituted into Eq. (10) we have:

$q_{\text {out }, i}=\varepsilon_{i} \sigma T_{i}^{4}+\left(1-\varepsilon_{i}\right) \sum_{j=1}^{N} F_{i j} q_{\text {out }, j}$ 
Eq. (14) can be written as:

$$
J_{i}-\left(1-\varepsilon_{i}\right) \sum_{j=1}^{N} F_{i j} J_{j}=E_{i}
$$

Also,

$$
J_{i}=E_{i}+\left(1-\varepsilon_{i}\right) \sum_{j=1}^{N} F_{i j} J_{j}
$$

$$
\sum_{j=1}^{N}\left(\delta_{i j}-\left(1-\varepsilon_{i}\right) F_{i j}\right) J_{j}=E_{i}
$$

where

$$
\delta_{i j}= \begin{cases}1 & \text { when } i=j \\ 0 & \text { when } i \neq j\end{cases}
$$

In vector form the equation for radiosity is expressed as:

$$
K J=E
$$

where $K=\left(\delta_{i j}-\left(1-\varepsilon_{i}\right) F_{i j}\right), J$ is the vector for radiosity, and $E$ is the vector for emissivity power.

The solutions for the above equations are used to predict the radiative Nusselt number.

The radiative heat transfer coefficient and its corresponding heat loss is expressed as: 


$$
h_{R}=\frac{N u k}{D}
$$

$Q_{R}=h_{R} A\left(T_{s}-T_{\infty}\right)$

Conduction has not been considered in this study since it is assumed to be minimum with appropriate insulation of the cavity receiver.

Therefore, the cavity receiver total heat loss is written as:

$$
Q_{\text {total }}=Q_{c}+Q_{R}
$$

\subsection{Thermal performance}

The thermal performance is estimated by estimating the incident power flux distribution using the Gaussian sun-shape. The overall receiver efficiency can be estimated as function of surface temperature and receiver aperture radius using equation from [30]. Though the assumption of Gaussian distribution is not suitable for high quality parabolic dishes, the difference in overall efficiency compared with the more accurate pillbox-shaped sun was found to be about $8 \%$ [30] justifying its use in the estimating of the overall efficiency in this study.

The solar energy absorption efficiency of a cavity receiver $\eta_{\text {absorption, }}$ defined as the net rate at which energy is being absorbed divided by the power coming from the concentrator. This is given by: 
$\eta_{\text {absorption }}=\frac{Q_{\text {net }}-Q_{\text {total }}}{P_{\text {in }}}$

$Q_{n e t}=\alpha_{\text {eff }} P_{\text {aperture }}$

$P_{i n}=2 \pi \lambda^{2} F_{p e a k}$

$$
P_{\text {aperture }}=2 \pi \lambda^{2} F_{\text {peak }}\left[1-\exp \left(\frac{-r^{2}}{2 \lambda^{2}}\right)\right]
$$

where $P_{\text {aperture }}$ is that amount of energy intercepted by the aperture, $F_{\text {peak }}$ is the peak flux, $\lambda$ denotes the standard deviation and $\alpha_{\text {eff }}$ is the effective absorptance. The overall idealized cavity receiver efficiency can be represented as:

$\eta_{\text {overall }}=\eta_{\text {absorption }}\left(1-\frac{T_{\infty}}{T_{s}}\right)$

In this analysis we assume $\alpha_{\text {eff }}=1$. For a given incident flux distribution, there is an optimum operating temperature and optimum radius for which overall efficiency is maximum. In this study, graph plotted using a simple method described by [30] is used to obtain the optimum operating temperatures used for a range flux distribution as shown in Table 1. 


\section{NUMERICAL PROCEDURE AND VALIDATION}

\subsection{Numerical procedure.}

STAR-CCM+ 7.06 a finite volume based CFD code was used in the 3D simulation of the heat loss through the aperture of the cavity receiver. Fig. 3 schematically represents computational grid of the cavity receiver. In reality, the receiver is surrounded by an infinite atmosphere with a limiting temperature equal to ambient air temperature. In the numerical analysis, the region outside the cavity is represented by a spherical enclosure (Fig. 3a) which was increased to a size such that the effect of heat and fluid flows within the vicinity of the cavity receiver was minor. To achieve this in STARCCM+, the diameter of the spherical enclosure was set to ten times the diameter of the receiver.

The core volume mesh contains polyhedral cells. The cells were refined on the walls of the cavity receiver as a percentage of base cell and prism layers cells were used on the walls of the cavity receiver (Fig. 3b). This led to cells being very small in the region near the cavity walls but gradually increasing towards the spherical enclosure wall. To create orthogonal prismatic cells in the area next the boundaries of the wall, the mesh model of prism layers with the core volume mesh was used. Fig. $3 \mathrm{~b}$ and c show an enlarged part of the mesh.

A mesh refinement was performed on the cavity receiver, investigating the average Nusselt number on the hot inner surfaces of the cavity receiver $\left(T_{\mathrm{s}}=800 \mathrm{~K}\right.$ and $\left.R a=10^{6}\right)$. Table 2 presents the average Nusselt numbers obtained for four different grids at two different inclination angles of the receiver $\left(\theta=0^{\circ}\right.$ and $\left.\theta=30^{\circ}\right)$. The relative deviation for the Nusselt number between grids 1 and 2 was less than $1 \%$. Since the differences between the two were minor, we chose grid 2 for all the 
simulations presented in this work. This was considered to be a good compromise between time cost and accuracy.

\subsubsection{Boundary Conditions}

Isothermal boundary condition was applied to the internal receiver surfaces, outer surface on the aperture plane as well as the fins. The temperature was varied from 800-1200 K. The outer spherical walls of the cavity receiver were considered as adiabatic since it was covered with insulation to prevent heat loss. The outer domain was treated as a pressure outlet boundary condition. The wall of the entire spherical enclosure was set to an ambient temperature of $300 \mathrm{~K}$. Film temperature was used to calculate the properties of the fluid in and around the cavity receiver.

\subsection{Validation}

To solve for natural convection and radiation, the non-Boussinesq model was used in this study. However, there is no distinct non-Boussinesq model for combined natural convection and radiation heat transfer for a modified hemispherical cavity receiver. Therefore, non-Boussinesq model at lower temperatures has been validated with low temperature Boussinesq models. The results of the Boussinesq and non-Boussinesq models are the same at low temperatures. The current numerical model was first validated with theoretical, numerical and experimental results reported by Khubeiz et al. [31] for 3-D laminar natural convection for an isothermal upward facing open hemispherical cavity. Good agreement was observed with the experimental data showing a maximum deviation of about $6.45 \%$ and the results are given in Table 3. This validation used glycerine as the working fluid and the isotherms at $R a$ of $1.1511 \times 10^{7}$ are shown in Figure 4. 
Secondly, natural convection Nusselt number correlations developed for the modified cavity receiver in [9] are compared with natural convection Nusselt numbers predicted from the current non-Boussinesq model and good agreement was observed with a maximum deviation of $4 \%$ as shown in Table 4. Since there is no three-dimensional data for radiation heat transfer for a modified cavity receiver, the predicted radiation Nusselt number from the present study are compared with the developed radiation Nusselt number correlation for a two-dimensional modified cavity model [29]. To achieve this, Grashof numbers of $10^{5}$ and $10^{6}$ at $400 \mathrm{~K}$ and emissivity of 0.5 and 1.0 have been taken. The results are given in Table 4. However, for radiation Nusselt number the deviation is up to $16.91 \%$ which is attributed to the fact that the present study used a 3-D model and is compared with a 2-D model. This is in agreement with prediction by Reddy and Kumar [9] that there is a deviation of about $14.5 \%$ between $2-\mathrm{D}$ and $3-\mathrm{D}$ simulations in a modified cavity receiver.

\subsection{Optimization problem formulation}

In this study, the optimization problem was designed towards finding the best plate fin geometric parameters, which give the least natural convection and radiation heat loss from the modified receiver cavity. The hydrodynamic performance of plate fins are significantly influenced by the plate fin heights and thicknesses. The dimensionless fin heights were varied in the range: $0.025 \leq$ $H_{j} / W \leq 0.15$. The dimensionless thicknesses of the fins were varied in the range: $0.025 \leq t_{j} / W \leq$ 0.125. The type of optimization considered in this study is the placement of individual plate fins to form channels. This leads to the treatment of an array of fins in which each fin is operating in an optimum manner [32]. 
The optimization problem was solved using Optimate+ an add-on to the CFD code Star CCM+ that adds the capability to perform automated design optimization studies using HEEDS (Hierarchical Evolutionary Engineering Design System) search algorithm called SHERPA (Systematic Hybrid Exploration that is Robust, Progressive, and Adaptive) [33]. Details of the process is explained in [34].

\section{RESULTS AND DISCUSSION}

\subsection{Effects of receiver inclination angle}

Fig. 5 and 6 show the variation of heat loss with receiver inclination angle for surface emissivity of 0.2 and 1.0 at $800 \mathrm{~K}$ operating temperature respectively. It is observed from both figures that the convective heat loss is maximum at $0^{\circ}$ (cavity aperture facing sideways towards the east) but starts to decrease as the inclination angle increases until a minimum is reached at $90^{\circ}$ when the receiver is facing downwards. This can be attributed to the fact that as the receiver inclination angle increases from $0^{\circ}$ to $90^{\circ}$ the receiver is initially dominated with the convective zone (where most of the heat transfer happens) at $0^{\circ}$, which starts to decrease with increasing inclination angle. At $90^{\circ}$ the cavity receiver is now dominated by the stagnant zone, thus convection heat loss out of the receiver is minimum.

From Fig. 5, it is observed that at lower emissivity (0.2), the convective heat loss is higher than the radiative heat loss at lower inclination angles $\left(0^{\circ}-50^{\circ}\right)$. This is due to the fact that the cavity is mostly occupied by the convective zone. However, for angles between $50^{\circ}$ and $90^{\circ}$ degrees, the radiative heat loss is higher than the convective heat loss. This can be attributed to the increase in the stagnation zone where convective heat loss is low. It observed from Fig.6 that the radiative heat 
loss dominates when the emissivity is increased to 1.0 for all inclination angles and the radiative heat is observed to remain constant at all inclination angles which means that radiative heat loss is not affected by the inclination angle.

\subsection{Effects of fin plates}

Fig. 7 shows the effects of fins on combined natural convection and radiation heat loss from the cavity receiver. Combined natural convection and radiation heat loss is plotted for different inclination angles for the cavity receiver without fins and the one with fins at $800 \mathrm{~K}$ operating temperature. It is observed from Fig. 7, that the inclusion of fins decreases both the natural convection and radiation heat loss from the cavity receiver. It is also observed in both cases that the radiative heat loss is more dominant and constant at all inclination angles. The decrease in convection heat transfer in the cavity receiver with plate fins is due to the decrease in the velocity of the fluid flowing through the cavities created by the insertion of plate fins. The fins increases the resistance of the convection cell movement between the plate fins thus further decreasing the convective heat loss. The conclusion is that the combined natural convection and radiation heat loss from the cavity receiver with fins was reduced compared to the case without fins. Convective heat loss is observed to have significantly reduced by approximately $20 \%$ at $0^{\circ}$ and $10 \%$ at $90^{\circ}$ with the introduction of fin plates. Radiation heat loss minimally reduced by $5 \%$ at all inclination angles.

\subsection{Effects of number of fins}

Fig. 8 shows the dependence of the combined natural convection and radiation heat loss on the number of plate fins on the aperture of the cavity receiver. Combined natural convection and radiation heat loss is plotted against the number of plate fins for different inclination angles, 
emissivity of 1.0 and fixed fin height and thickness. It is observed from Fig. 8 that, there is a decrease in combined natural convection and radiation heat loss at all inclination angles of the cavity receiver, when the number of plate fins is increased. This decrease is due to the decrease in the flow intensity with the insertion of plate fins. Increasing the number of fins leads to weaker flow intensity due to the expected increased resistance of motion of the rotating convection cells. Weaker flow intensity lowers the heat transfer rate thus decreasing the natural convection heat loss and ultimately the total heat loss.

\subsection{Effects of surface emissivity}

The effect of surface emissivity on total heat loss from the cavity receiver was investigated for different inclination angles. For a given Rayleigh number and temperature, the total heat loss varies linearly with emissivity for all inclination angles as seen from Fig. 9. There is a sharp increase in the total heat loss with increasing surface emissivity. This can be attributed to the fact that radiative heat loss increases with increasing emissivity in the receiver. Surface radiation is directly affected by the surface emissivity of the cavity receiver thus increasing the radiative heat loss and the total heat loss as a whole. The most heat loss occurs at $90^{\circ}$ and 1.0 emissivity and the least total heat loss is estimated at $0^{\circ}$ when the emissivity is 0.2 . Based on this observation, it would therefore be important to use selective coating on the tubing and inner walls of the cavity receiver which would help reduce the radiative heat loss and ultimately the total heat loss.

\subsection{Effects of surface temperature}

To observe the effects of temperature on combined natural convection and radiation heat transfer, the temperature of the cavity receiver was varied from $800 \mathrm{~K}$ to $1200 \mathrm{~K}$. For a given dimensionless 
fin height $(H / W=0.125 \mathrm{~m})$, fin thickness $(t / W=0.075 \mathrm{~m})$, emissivity $(1.0)$ and Rayleigh number $\left(1 \times 10^{6}\right)$, the temperature contours of the cavity receiver at a given inclination angle and surface temperatures are shown in Fig. 10a. and 10b. It is observed from the cavity receiver at $800 \mathrm{~K}$ and at $60^{\circ}$ inclination angle (Fig. 10a) that, the thickness of the stagnation zone in the top part of the cavity is higher compared to that of the corresponding cavity at $1200 \mathrm{~K}$ (Fig. 10b). It is seen in both cases that the upper parts of the walls have higher temperatures compared to the lower parts of the cavity receiver walls. As air at ambient temperature is driven into the cavity receiver by the natural convective currents, the air adjacent to the receiver surface heats up and becomes light after absorbing heat from the receiver surfaces and consequently flows up along the cavity wall. This results in stagnant hot air only appearing at the top of the cavity receiver. Eventually, the hot air exits the cavity through its aperture and thereafter cooled by the ambient. The temperature contours are distorted by the flow and the fluid penetrates through into the cavity. It is observed that the fluid penetrates more into the cavity at high temperature (Fig.10b) compared to the cavity at lower temperature (Fig. 10a). It is also noted that the thickness of the hydrodynamic boundary layer adjacent to the hot wall decreases in both cases as the temperature increases.

Fig. 11 shows the variation of combined natural convection and radiation heat loss with temperature for a given emissivity, Rayleigh number at different inclination angles of the cavity receiver. It is observed from the graph that radiation heat loss varies greatly with increasing temperature but remains constant for all inclination angles while natural convection heat loss varies steadily with increasing temperature and also depends on the inclination angle of the receiver. It is also observed that natural convection is minimum at $90^{\circ}$ and highest at $0^{\circ}$. Because of the higher radiation heat loss which is constant at all inclination angles, the total heat loss is also high and varies greatly with temperature. It is important therefore to reduce the temperature of the receiver surfaces to avoid 
large radiation and convection losses from these surfaces and this can be achieved by using selective coating with low emissivity for the cavity receiver wall surfaces.

\subsection{Optimization results}

In this study, the optimization algorithm SHERPA was used to get the best geometric shape of the plate fins that will optimally suppress combined natural convection and radiation heat loss in a cavity receiver. The optimal geometric parameters have significant influence on the performance of the receiver cavity as the reduction of total heat loss will improve the performance of the cavity receiver. For each simulation, 30 optimization numerical evaluations were conducted automatically within the constraint ranges given in section 4.0 and convergence was attained after approximately 14 hours. The results are presented in Table 5.

\subsection{Thermal efficiency}

Figs. 12 and 13 illustrate the change trends of overall cavity receiver efficiency when the optimum operating temperature varies from $800 \mathrm{~K}$ to $1200 \mathrm{~K}$. The results show that the overall cavity receiver efficiency increases with increasing operating temperature. It is observed from Fig. 12 that the overall cavity receiver efficiency varies marginally with increasing inclination angle. The cavity receiver at $90^{\circ}$ is seen to have a slight higher efficiency compared to when the cavity receiver is at $0^{\circ}$. This is attributed to the fact that there is higher convective heat loss at this angle as discussed in section 4.1 .

It is observed from Fig. 13 that, the increase of overall cavity efficiency is marginally at approximately $2 \%$ with the insertion of fin plates although the convective heat loss decreases by 
$20 \%$. This is due to the fact that radiation heat loss dominates at high operating temperatures compared to convective heat loss and this supports the conclusion by other researchers. From Fig. 13, we observe that the cavity overall efficiency increases with the introduction of fin plates and optimum geometry exits as the results show in Table 5 for maximum cavity receiver efficiency.

\section{CONCLUSIONS}

The numerical study of combined laminar natural convection and surface radiation heat transfer in cavity receiver with plate fins was presented in this paper. The effect of surface emissivity, operating temperature, orientation and the geometric parameters on the total heat loss from the receiver was investigated. It was observed that convective heat loss is largely affected by the angle of inclination of the receiver, the presence of fins and the number of fins in the receiver. As for the radiation heat loss it was observed that it is mainly influenced by surface properties of the cavity receiver. The radiative heat was observed to be constant at all inclination angles. The key conclusion is that substantial reduction in natural convection heat loss of about $20 \%$ from the cavity receiver was attained with the use of plate fins while radiation heat loss was marginally reduced by about $5 \%$. The overall cavity efficiency marginally increased by approximately $2 \%$ with the insertion of fin plates although the convective heat loss was suppressed by about $20 \%$. This is due to the fact that radiation heat loss dominates at high operating temperatures compared to convective heat loss and this supports the conclusion by other researchers that radiation heat loss dominates at higher temperatures. The results obtained in this study provide a novel approach for improving the design of cavity receivers for optimal performance.

\section{ACKNOWLEDGMENT}

The funding from National Research Foundation and University of Pretoria is acknowledged by the authors 


\section{REFERENCES}

[1] D. J. Reynolds, M. J. Jance, M. Behnia, and G. L. Morrison, "An experimental and computational study of the heat loss characteristics of a trapezoidal cavity absorber," Sol. Energy, vol. 76, no. 1-3, pp. 229-234, Jan. 2004.

[2] R. Bertocchi, J. Karni, and A. Kribus, "Experimental evaluation of a non-isothermal high temperature solar particle receiver," Energy, vol. 29, no. 5-6, pp. 687-700, Apr. 2004.

[3] R. Ben-Zvi and J. Karni, "Simulation of a Volumetric Solar Reformer," J. Sol. Energy Eng., vol. 129, no. 2, p. 197, 2007.

[4] J. A. Harris and T. G. Lenz, "Thermal performance of solar concentrator/cavity receiver systems," Sol. Energy, vol. 34, no. 2, pp. 135-142, Jan. 1985.

[5] A. M. Clausing, "Convective Losses From Cavity Solar Receivers-Comparisons Between Analytical Predictions and Experimental Results," ASME J. Sol. Energy Eng., vol. 105, no. 1, pp. 2933, 1983.

[6] P. Siangsukone and K. Lovegrove, "Modelling of a 400m steam based Paraboloidal Dish concentrator for solar thermal power production," 2003, November, pp. 79-85.

[7] N. Sendhil Kumar and K. S. Reddy, "Numerical investigation of natural convection heat loss in modified cavity receiver for fuzzy focal solar dish concentrator," Sol. Energy, vol. 81, no. 7, pp. 846855, Jul. 2007.

[8] N. Sendhil Kumar and K. S. Reddy, "Comparison of receivers for solar dish collector system," Energy Convers. Manag., vol. 49, no. 4, pp. 812-819, Apr. 2008.

[9] K. S. Reddy and N. Sendhil Kumar, "An improved model for natural convection heat loss from modified cavity receiver of solar dish concentrator," Sol. Energy, vol. 83, no. 10, pp. 1884-1892, Oct. 2009.

[10] M. Prakash, S. B. Kedare, and J. K. Nayak, "Investigations on heat losses from a solar cavity receiver," Sol. Energy, vol. 83, no. 2, pp. 157-170, Feb. 2009.

[11] S. Y. Wu, L. Xiao, and Y. R. Li, "Effect of aperture position and size on natural convection heat loss of a solar heat-pipe receiver," Appl. Therm. Eng., vol. 31, no. 14-15, pp. 2787-2796, Oct. 2011.

[12] C. X. Lin, S. Y. Ko, and M. D. Xin, "Effects of surface radiation on turbulent free convection in an open-ended cavity," Int. Commun. Heat Mass Transf., vol. 21, no. 1, pp. 117-129, Jan. 1994.

[13] C. Balaji and S. P. Venkateshan, "Interaction of radiation with free convection in an open cavity," Int. J. Heat Fluid Flow, vol. 15, no. 4, pp. 317-324, Aug. 1994.

[14] S. Singh and S. Venkateshan, "Numerical study of natural convection with surface radiation in sidevented open cavities," Int. J. Therm. Sci., vol. 43, no. 9, pp. 865-876, Sep. 2004. 
[15] J. F. Hinojosa, R. E. Cabanillas, G. Alvarez, and C. E. Estrada, "Nusselt number for the natural convection and surface thermal radiation in a square tilted open cavity," Int. Commun. Heat Mass Transf., vol. 32, no. 9, pp. 1184-1192, Oct. 2005.

[16] J. F. Hinojosa, C. A. Estrada, R. E. Cabanillas, and G. Alvarez, "Numerical Study of Transient and Steady-State Natural Convection and Surface Thermal Radiation in a Horizontal Square Open Cavity," Numer. Heat Transf. Part A Appl., vol. 48, no. 2, pp. 179-196, Jul. 2005.

[17] K. S. Reddy and N. Sendhil Kumar, "Convection and surface radiation heat losses from modified cavity receiver of solar parabolic dish collector with two-stage concentration," Heat Mass Transf., vol. 45, no. 3, pp. 363-373, Sep. 2008.

[18] N. Sendhil Kumar, "Investigation of convection and radiation heat losses from modified cavity receiver of solar parabolic dish using asymptotic computational fluid dynamics," Heat Transf. Eng., vol. 31, no. 7, pp. $597-607,2010$.

[19] M. Gonzalez, J. Hinojosa, and C. A. Estrada, "Numerical study of heat transfer by natural convection and surface thermal radiation in an open cavity receiver," Sol. Energy, vol. 86, no. 4, pp. 1118-1128, Apr. 2012.

[20] N. Ramesh and W. Merzkirch, "Combined convective and radiative heat transfer in side-vented open cavities,” Int. J. Heat Fluid Flow, vol. 22, no. 2, pp. 180-187, Apr. 2001.

[21] Y. Tan, L. Zhao, J. Bao, and Q. Liu, "Experimental investigation on heat loss of semi-spherical cavity receiver," Energy Convers. Manag., vol. 87, pp. 576-583, Nov. 2014.

[22] A. Kribus, P. Doron, R. Rubin, J. Karni, R. Reuven, S. Duchan, and E. Taragan, "A Multistage Solar Receiver:," Sol. Energy, vol. 67, no. 1-3, pp. 3-11, Jul. 1999.

[23] T. Hahm, H. Schmidt-Traub, and B. Lebmann, "A cone concentrator for high-temperature solar cavity receivers," Sol. Energy, vol. 65, no. 1, pp. 33-41, Jan. 1999.

[24] W. G. Le Roux, T. Bello-Ochende, and J. P. Meyer, "The efficiency of an open-cavity tubular solar receiver for a small-scale solar thermal Brayton cycle," Energy Convers. Manag., vol. 84, pp. 457470, Aug. 2014.

[25] R. Rubin J. Karni, A. Kribus, "The 'porcupine': A novel high-flux absorber for volumetric solar receivers," J. Sol. Energy Eng. ASME, vol. 120, no. 2, pp. 85-95, 1998.

[26] F. Chen, M. Li, P. Zhang, and X. Luo, "Thermal performance of a novel linear cavity absorber for parabolic trough solar concentrator," Energy Convers. Manag., vol. 90, pp. 292-299, Jan. 2015.

[27] F. Cui, Y. He, Z. Cheng, and Y. Li, "Study on combined heat loss of a dish receiver with quartz glass cover," Appl. Energy, vol. 112, pp. 690-696, Dec. 2013.

[28] A. I. Zografos, W. A. Martin, and J. E. Sunderland, "Equations of properties as a function of temperature for seven fluids," Comput. Methods Appl. Mech. Eng., vol. 61, no. 2, pp. 177-187, Mar. 1987.

[29] K. S. Reddy and N. Sendhil Kumar, "Combined laminar natural convection and surface radiation heat transfer in a modified cavity receiver of solar parabolic dish," Int. J. Therm. Sci., vol. 47, no. 12, pp. 1647-1657, Dec. 2008. 
[30] A. Steinfeld and M. Schubnell, "Optimum aperture size and operating temperature of a solar cavityreceiver,” Sol. Energy, vol. 50, no. 1, pp. 19-25, Jan. 1993.

[31] J. M. Khubeiz, E. Radziemska, and W. M. Lewandowski, "Natural convective heat-transfers from an isothermal horizontal hemispherical cavity,” Appl. Energy, vol. 73, no. 3-4, pp. 261-275, Nov. 2002.

[32] W. J. Kraus A., Aziz A., Extended Surface heat transfer. John Wiley \& Sons, Inc, 2007.

[33] Red Cedar Technology, "HEEDS (Hierarchical Evolutionary Engineering Design System). Getting Started Manual.” 2011.

[34] L. C. Ngo, T. Bello-Ochende, and J. P. Meyer, "Numerical modelling and optimisation of natural convection heat loss suppression in a solar cavity receiver with plate fins," Renew. Energy, vol. 74, pp. 95-105, Feb. 2015. 


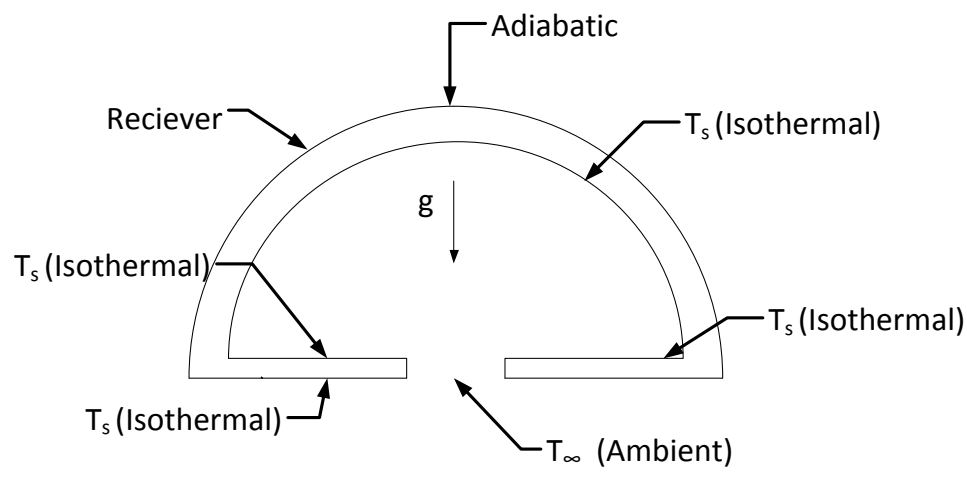

(a)

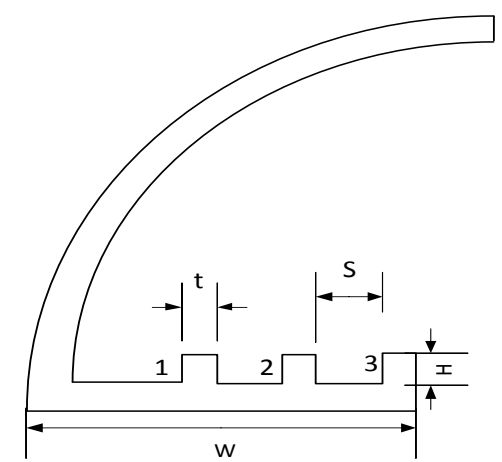

(b)

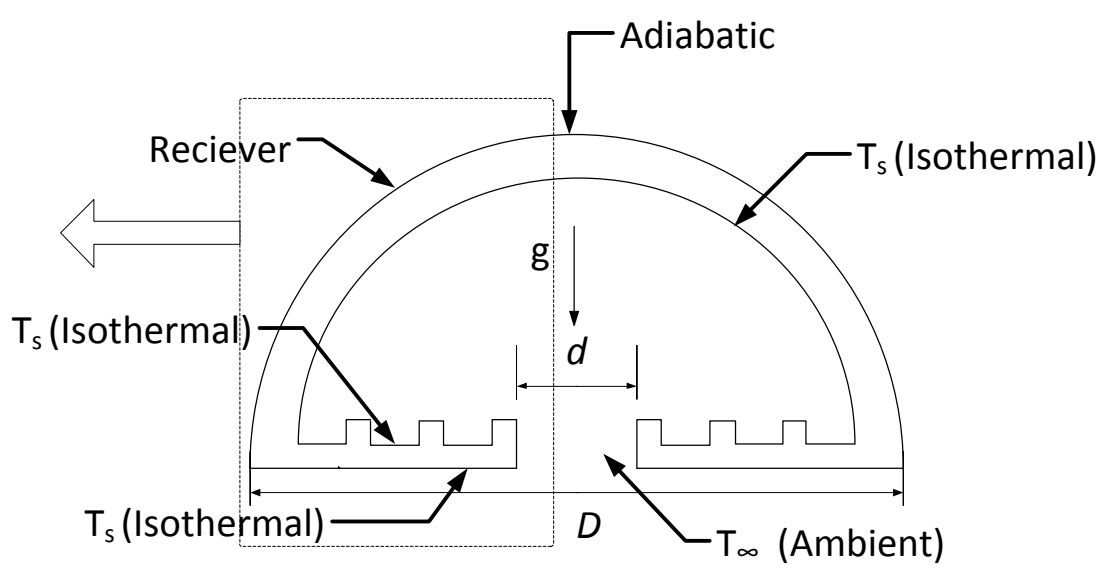

(c)

Fig.1 Schematic of modified cavity receiver with and without plate fins 


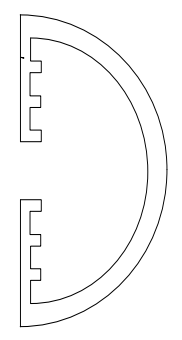

(a)

0 degrees

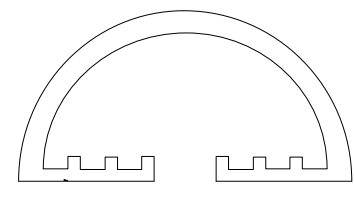

(b)

90 degrees

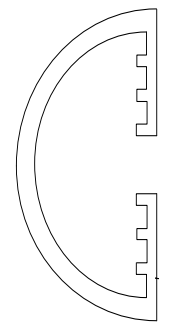

(c)

180 degrees

Fig.2 Schematic of modified cavity receiver at different inclination angles 

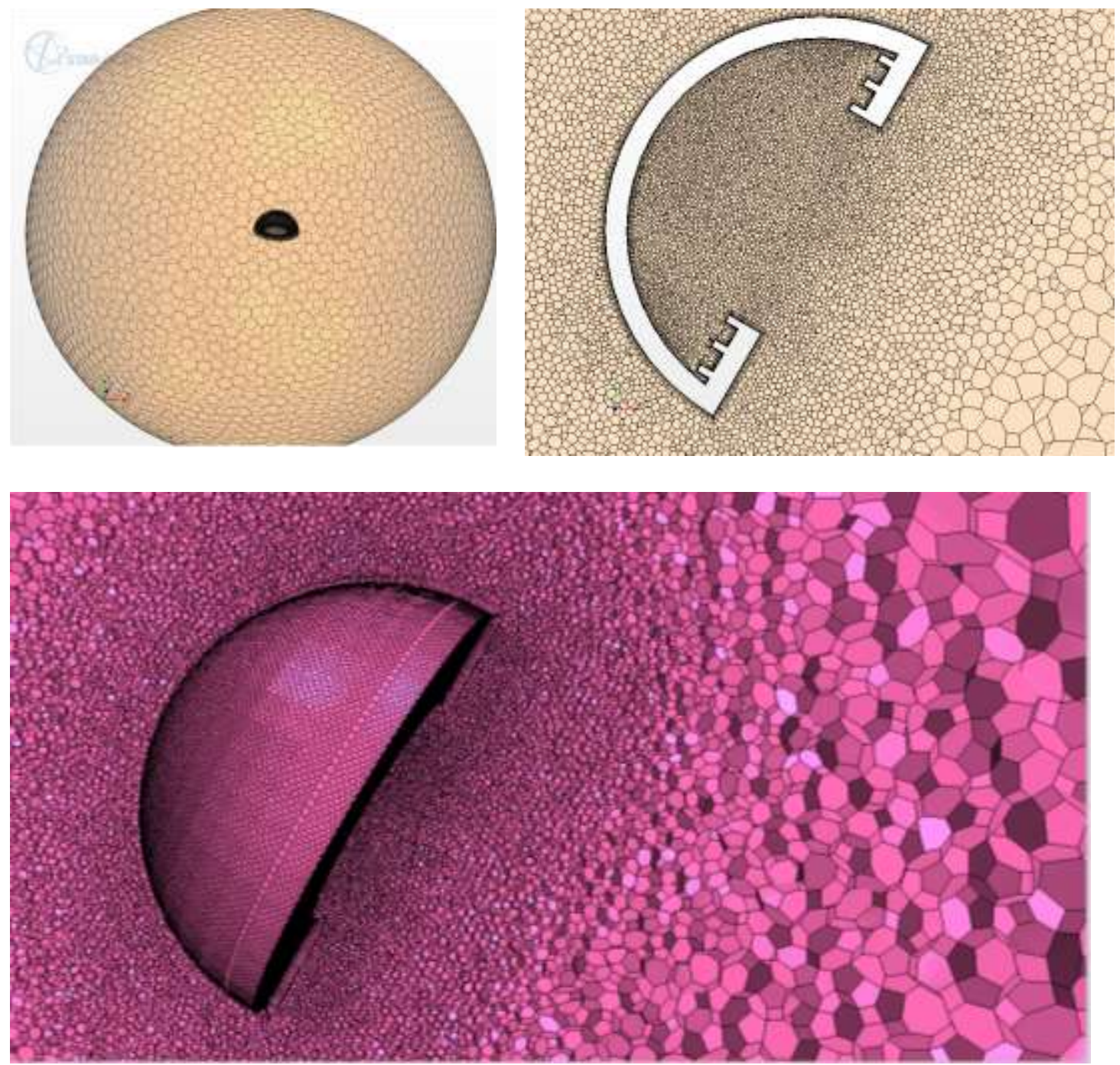

Fig. 3. Computational grid for the numerical analysis of the modified cavity receiver (a) 3-D including sphere (b) 2-D cross-section at $30^{\circ}$ (c) refined polyhedral cells are in and around the cavity at $30^{\circ}$ and the coarse mesh towards the sphere. 

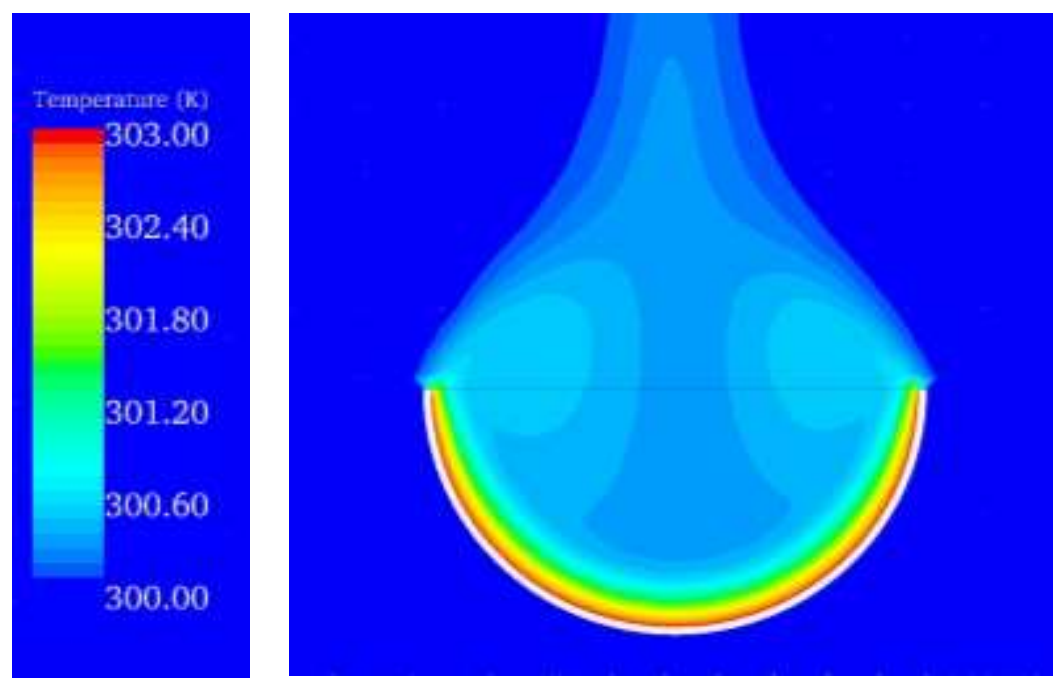

Figure 4 Temperature contours of mid plane of upward open hemispherical cavity 


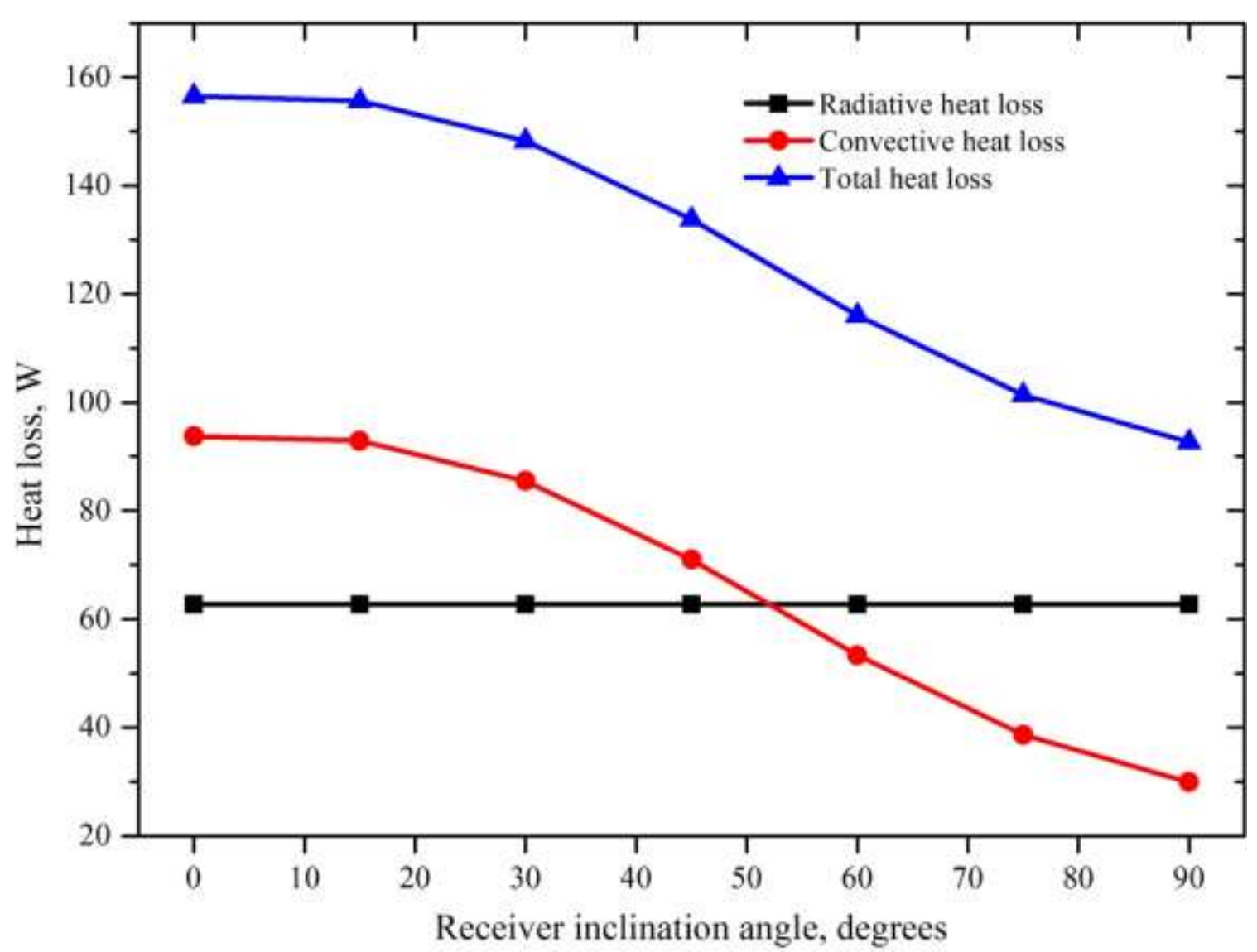

Fig. 5 Variation of heat loss with cavity receiver inclination angle, $\varepsilon=0.2$ at $800 \mathrm{~K}$ 


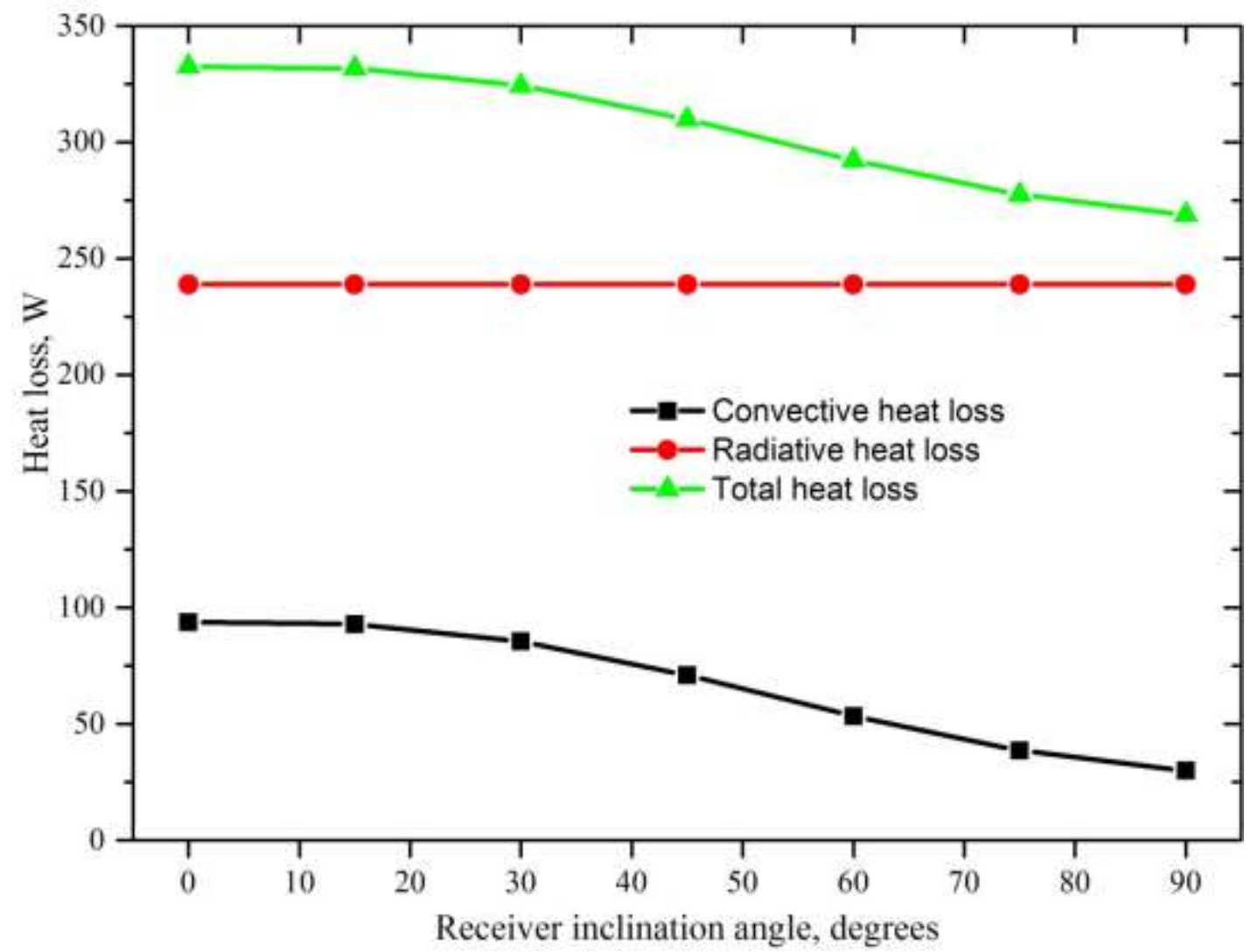

Fig. 6 Variation of heat loss with cavity receiver inclination angle, $\varepsilon=1.0$ at $800 \mathrm{~K}$ 


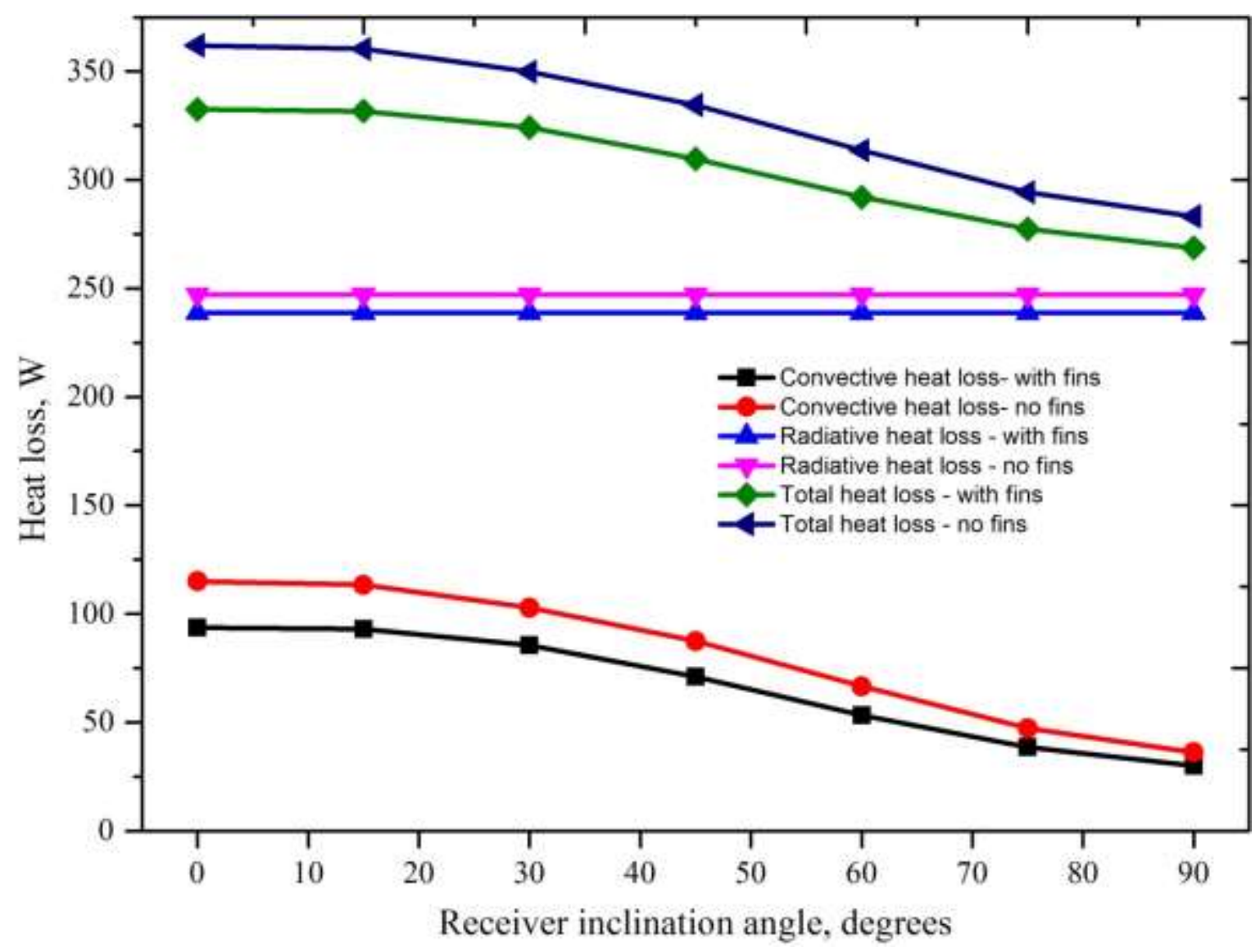

Fig. 7 Variation of combined natural convection and radiation heat loss with receiver cavity inclination angle $800 \mathrm{~K}$ operating temperature. 


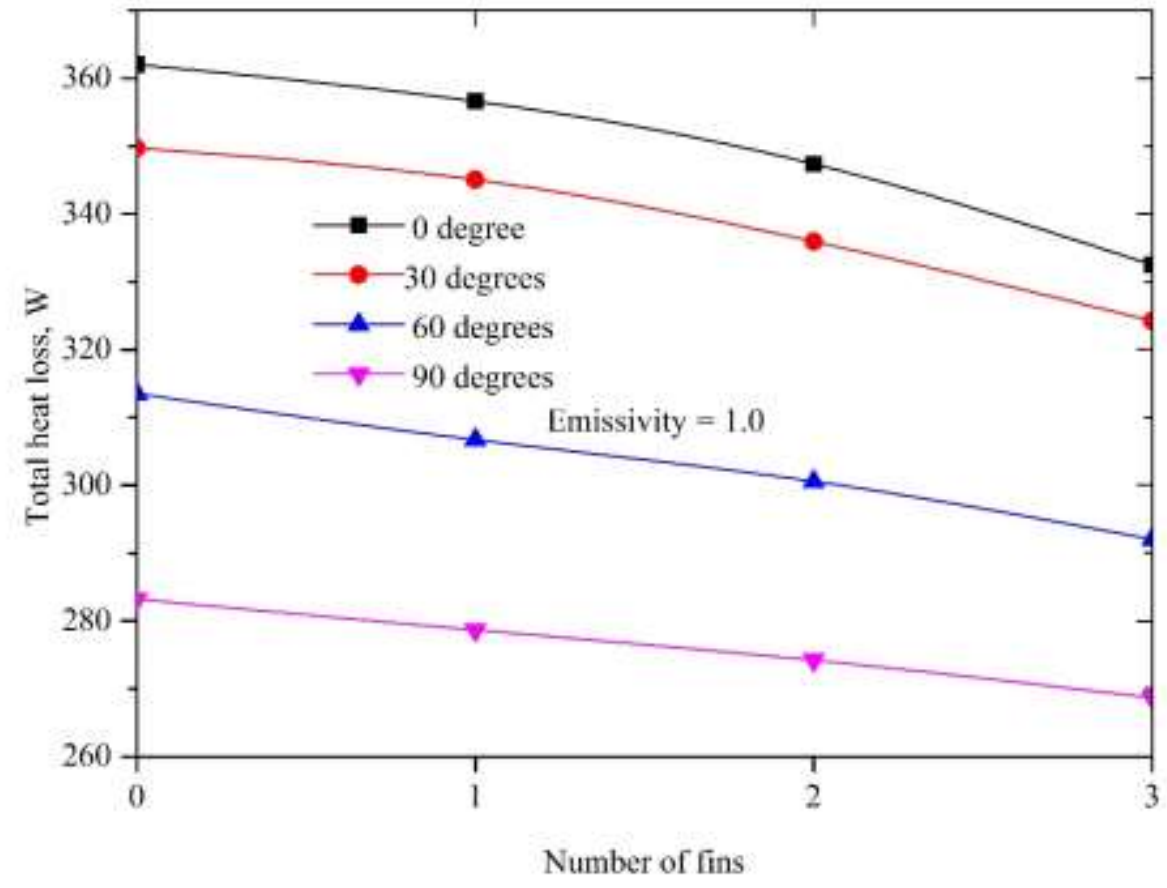

Fig. 8 Variation of combined natural convection and radiation heat loss with number of fins 


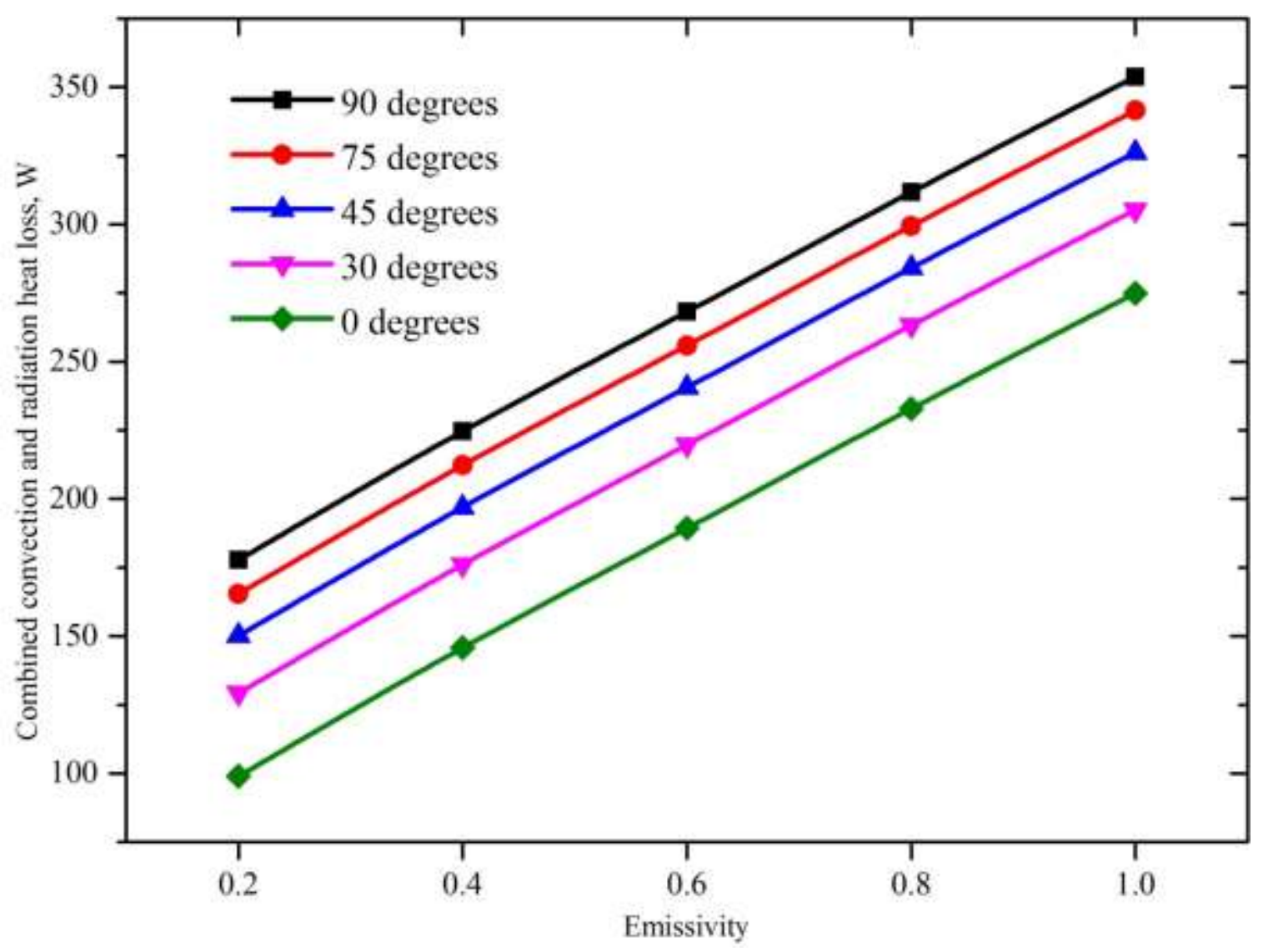

Fig. 9 Variation of combined natural convection and radiation heat loss with receiver cavity emissivity at $800 \mathrm{~K}$. 


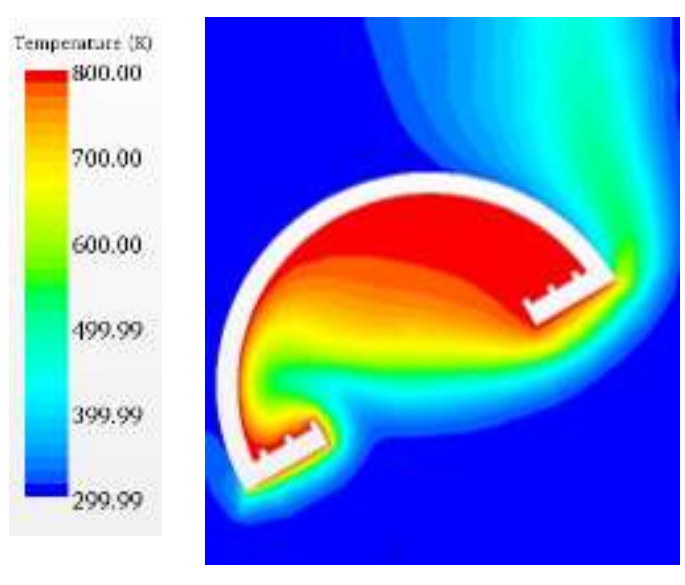

(a)

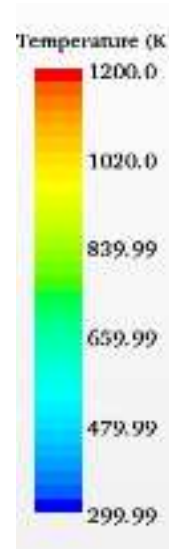

(b)

Fig. 10 Temperature contours for cavity receiver with three plate fins at 60 degrees for $\mathrm{Ra}=10^{6}$ with surface temperature at $800 \mathrm{~K}$ and $1200 \mathrm{~K}$ 


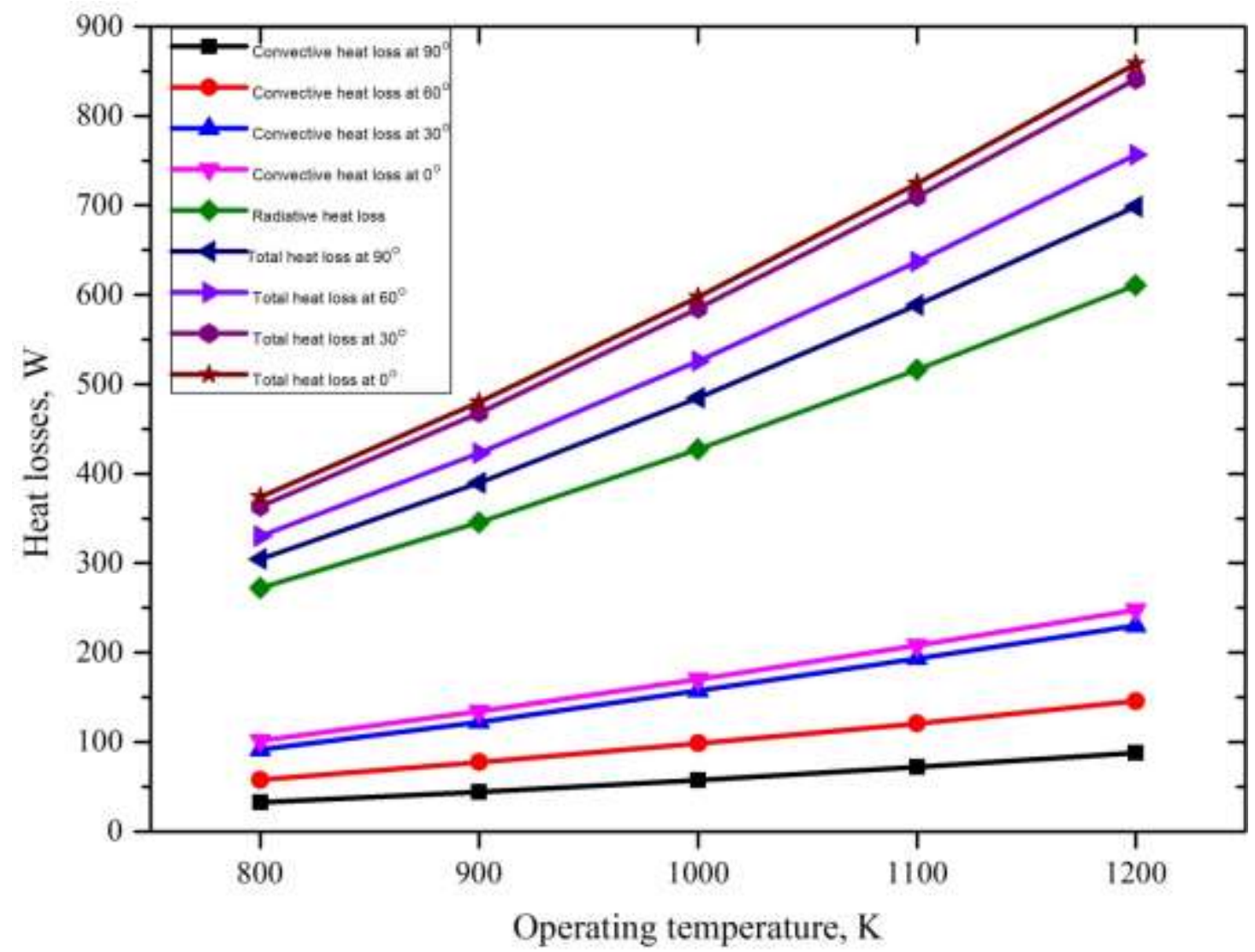

Fig. 11 Variation of combined natural convection and radiation heat loss with temperature. 


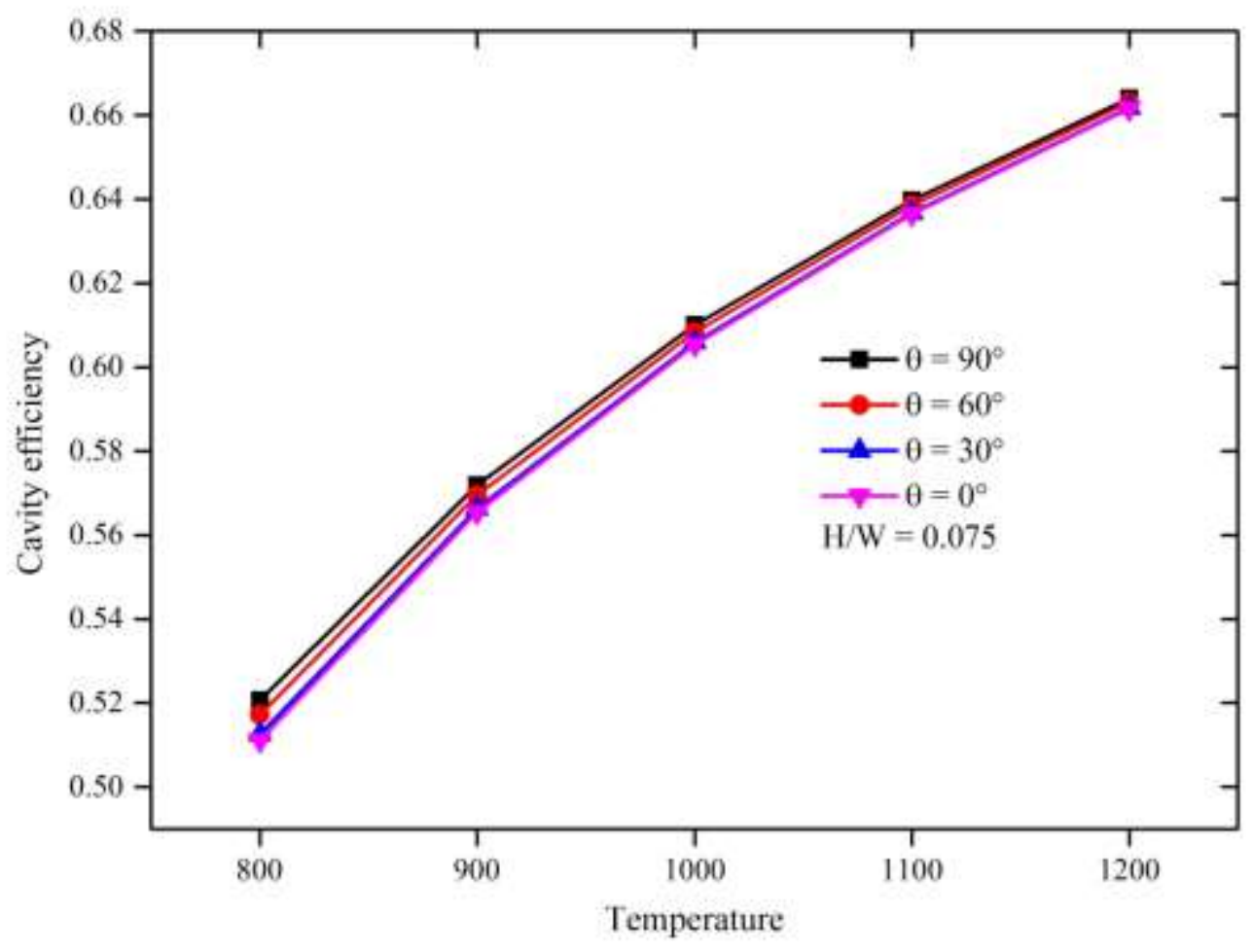

Fig. 12 Variation of cavity receiver efficiency and optimum operating temperature. 


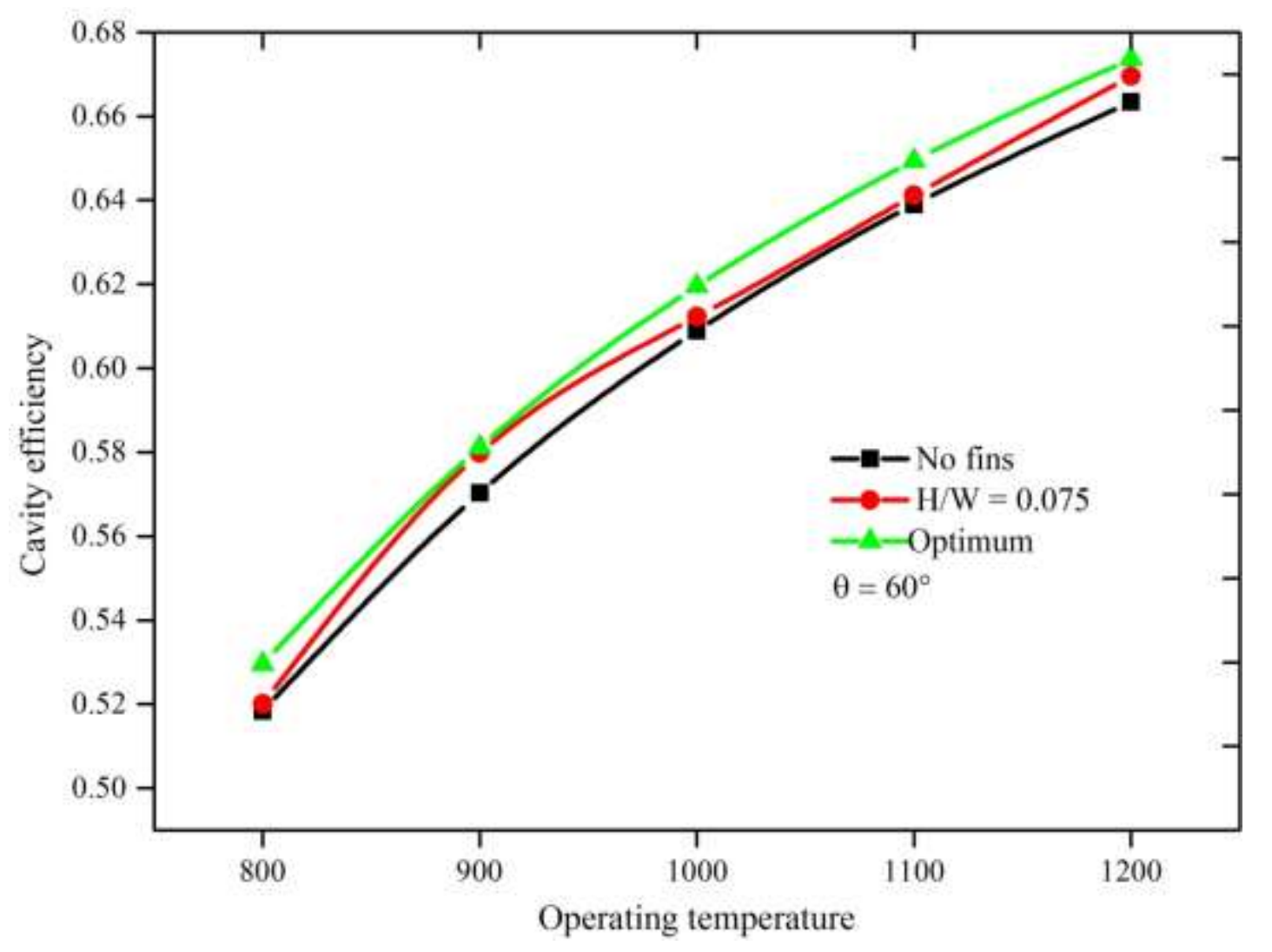

Fig. 13 Variation of cavity receiver efficiency and optimum operating temperature. 


$$
0.58
$$

1.18

2.17

3.70

6.08
800

900

1000

1100

12000

Table 1 Peak flux density and corresponding operating temperature 


\begin{tabular}{|c|c|c|c|c|}
\hline \multirow[t]{3}{*}{ Cells } & \multicolumn{4}{|c|}{ Nusselt number } \\
\hline & $\theta=0^{\circ}$ & Relative & $\theta=30^{\circ}$ & Relative \\
\hline & \multicolumn{3}{|c|}{ Deviation } & Deviation \\
\hline 801,337 & 10.1675 & & 18.2941 & \\
\hline 320,000 & 10.1529 & 0.001436 & 18.2734 & 0.001132 \\
\hline 241,336 & 10.2338 & -0.00797 & 18.2008 & 0.003973 \\
\hline 218,272 & 10.2947 & -0.00595 & 18.2096 & -0.00048 \\
\hline
\end{tabular}

Table 2 Average Nusselt numbers for different grids 


\begin{tabular}{|c|c|c|c|c|c|}
\hline \multirow[t]{2}{*}{$\begin{array}{l}\text { Rayleigh } \\
\text { number }\end{array}$} & \multicolumn{3}{|c|}{$\begin{array}{l}\text { Nusselt number from } \\
\text { Khubeiz et al. [31] }\end{array}$} & \multirow[t]{2}{*}{$\begin{array}{l}\text { Nusselt number from } \\
\text { present numerical } \\
\text { procedure }\end{array}$} & \multirow[t]{2}{*}{$\begin{array}{l}\text { Percentage of deviation } \\
\text { from experimental } \\
\text { value }\end{array}$} \\
\hline & $\mathrm{Nu}_{\text {exp }}$ & $\mathrm{Nu}_{\mathrm{num}}$ & $\mathrm{Nu}_{\text {anal }}$ & & \\
\hline $2.4864 \times 10^{6}$ & 12.55 & 13.50 & 11.75 & 11.74 & 6.45 \\
\hline $1.1511 \times 10^{7}$ & 18.41 & 19.80 & 17.24 & 18.82 & -2.23 \\
\hline
\end{tabular}

Table 3 Validation of the present numerical procedure using experimental convective Nusselt number 


\begin{tabular}{llllll}
\hline Configuration & Grashof & Nusselt number & \multicolumn{2}{l}{ Nusselt number } & $\%$ \\
\cline { 4 - 5 } & number & & Reported & Present study & Deviation \\
\hline Modified cavity [9] & $1.4085 \times 10^{6}$ & Convective- $90^{\circ}$ & 12.43 & 12.25 & 1.45 \\
\cline { 5 - 6 } Improved & & Convective - $75^{\circ}$ & 15.53 & 16.00 & 3.03 \\
& $1.4085 \times 10^{5}$ & Convective- $90^{\circ}$ & 7.68 & 7.99 & -4.04 \\
& & Convective $-75^{\circ}$ & 9.60 & 9.26 & 3.76 \\
Modified cavity [29] & $1.4085 \times 10^{6}$ & Radiative- $\varepsilon=0.5$ & 11.56 & 12.56 & -8.65 \\
& & Radiative- $\varepsilon=1.0$ & 16.87 & 14.02 & 16.91 \\
\hline
\end{tabular}

Table 4 Numerical validation procedure for natural convection and radiation heat loss 


\begin{tabular}{|l|l|l|}
\hline \multirow{2}{*}{ Variable } & \multicolumn{2}{|c|}{ Fin Height/Thickness (m) } \\
\cline { 2 - 3 } & Initial & Optimized \\
\hline H1 & 0.005 & 0.006 \\
\hline H2 & 0.005 & 0.006 \\
\hline H3 & 0.005 & 0.006 \\
\hline t1 & 0.003 & 0.005 \\
\hline t2 & 0.003 & 0.005 \\
\hline t3 & 0.003 & 0.005 \\
\hline
\end{tabular}

Table 5 Optimization results 